Jose M. Carnate, Jr,,MD

Department of Pathology

College of Medicine

University of the Philippines Manila

Correspondence: Jose M. Carnate, Jr.,MD

Department of Pathology

College of Medicine

University of the Philippines Manila

547 Pedro Gil St., Ermita, Manila 1000

Philippines

Phone: (632) 5264550

Fax: (632) 4003638

Email: jmcjpath@yahoo.com

Reprints will not be available from the author.

The author declared that this represents original material that is not being considered for publication or has not been published or accepted for publication elsewhere, in full or in part, in print or electronic media; that the manuscript has been read and approved by the author, that the requirements for authorship have been met by the author, and that the author believes that the manuscript represents honest work.

Disclosures: The author signed a disclosure that there are no financial or other (including personal) relationships, intellectual passion, political or religious beliefs, and institutional affiliations that might lead to a conflict of interest.
Olfactory neuroblastomas (esthesioneuroblastomas, ONB) are rare malignant neoplasms that arise from sensory neuroepithelial (neuroectodermal) olfactory cells found in the superior nasal concha and the cribriform plate of the ethmoid sinus. ONBs comprise approximately $5 \%$ of sinonasal tract malignancies, affect both genders equally and primarily involve the middle aged adult group (range 3 - 79 years). The most common presenting symptoms are unilateral nasal obstruction, epistaxis and a fairly slow-growing mass high in the nasal cavity or ethmoid region. Anosmia is also characteristic. A classic, though advanced, radiologic presentation is that of a "dumbbell-shaped" mass on either side of the cribriform plate, with an expansion into the nasal vault and an opposite expansion into the intracranial cavity. $1,2,3$

We present here two illustrative cases. The first is a 67-year-old male who has had three recurrences of a left nasal mass over a span of 24 years. The initial occurrence was treated with excision and radiotherapy while subsequent recurrences were treated with excision alone. The material shown herein is from the latest recurrence. All previous slides were not available for review. The second case is a 52-year-old male who presented with a six-month history of a right nasal cavity mass that on initial consult already extended into the maxillary, ethmoid, sphenoid and bilateral frontal sinuses, penetrated the cribriform sinus and involved the right frontal lobe of the brain. A craniofacial resection was performed.

The typical case is best described as a "malignant small round cell tumor" arranged in rounded lobules in a vascularized stroma (Figure1). This general architecture is found irrespective of the grade of the tumor. The cells are neuroendocrine in appearance with uniform small round nuclei that have "salt-and-pepper" nuclear chromatin (Figure 2) and scanty cytoplasm. Tumors are graded according to the Hyams' grading system. Grades $1-2$ tumors have nil to few mitoses, minimal nuclear pleomorphism, absent necrosis and presence of Homer-Wright pseudorosettes (Figure 3), while Grades 3-4 tumors have brisk mitoses, prominent nuclear pleomorphism, frequent necrosis and predominance of Flexner-Wintersteiner true rosettes (Figures 4,5). The first case is an example of a Grade 2 ONB while the second shows a Grade 4 morphology. Immunohistochemistry typically shows diffuse positivity for the neuroendocrine markers neuron-specific enolase, chromogranin and synaptophysin (Figure 6), and negative reactions for cytokeratins, desmin and CD99. The latter three stains are significant in that the differential diagnoses include Sinonasal Undifferentiated Carcinomas (SNUC), Rhabdomyosarcomas and Primitive Neuroectodermal Tumors/Ewing Sarcomas (PNET/ES) in which these stains are expected to be positive, respectively. ${ }^{1,3}, 4$ Other differential diagnosis include a Non-Hodgkin Lymphoma and a Mucosal Malignant Melanoma for which a Leukocyte Common Antigen (LCA) and melanoma markers (e.g. HMB-45 or Melan-A) may be performed. The two cases were however sufficiently distinct as to rule out these two entities on morphologic grounds. 
Prognosis is stage - (90\% 5-year survival rate for early-stage versus $40 \%$ foradvanced-stagecases) and grade-dependent ( $80 \%$ forlow-grade versus $40 \%$ for high-grade cases). Recurrence occurs in approximately $30 \%$ of cases usually within two years. The long-term recurrences seen in the first case is compatible with its low-grade morphology. In contrast, the shorter history and high stage (Kadish stage $\mathrm{C})^{4}$ at presentation of the second case are both compatible with its high-grade morphology. Metastases develop in about $20 \%$ of cases and usually involve the lymph nodes, lungs and bone. Complete surgical excision with postoperative radiotherapy is the mainstay of treatment. ${ }^{1,2}$

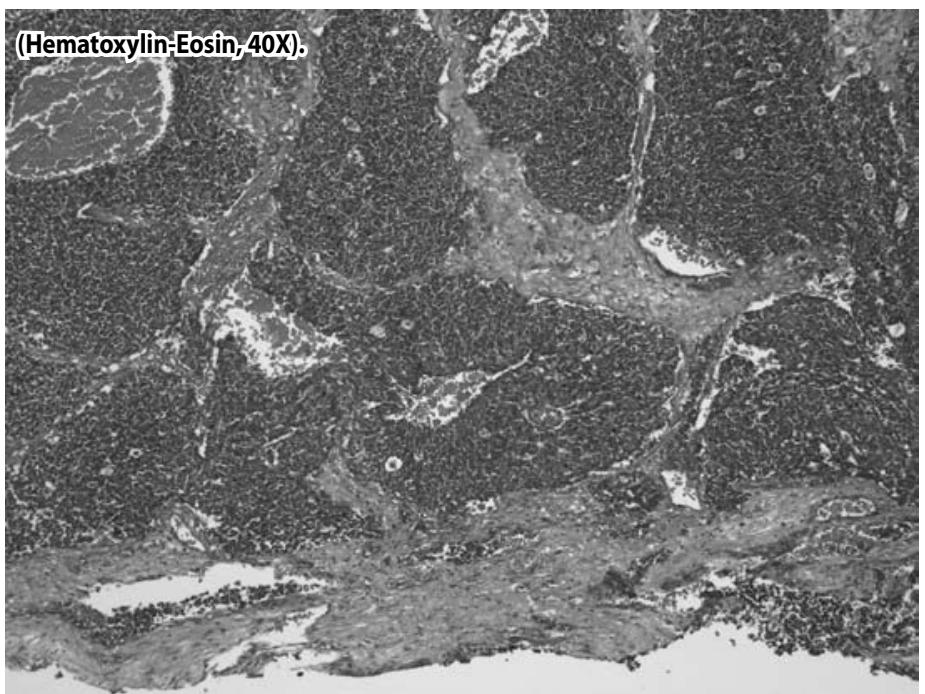

Figure 1. Case 2 - Rounded lobules of cohesive tumor cells separated by a vascularized stroma (Hematoxylin-Eosin, 40X).

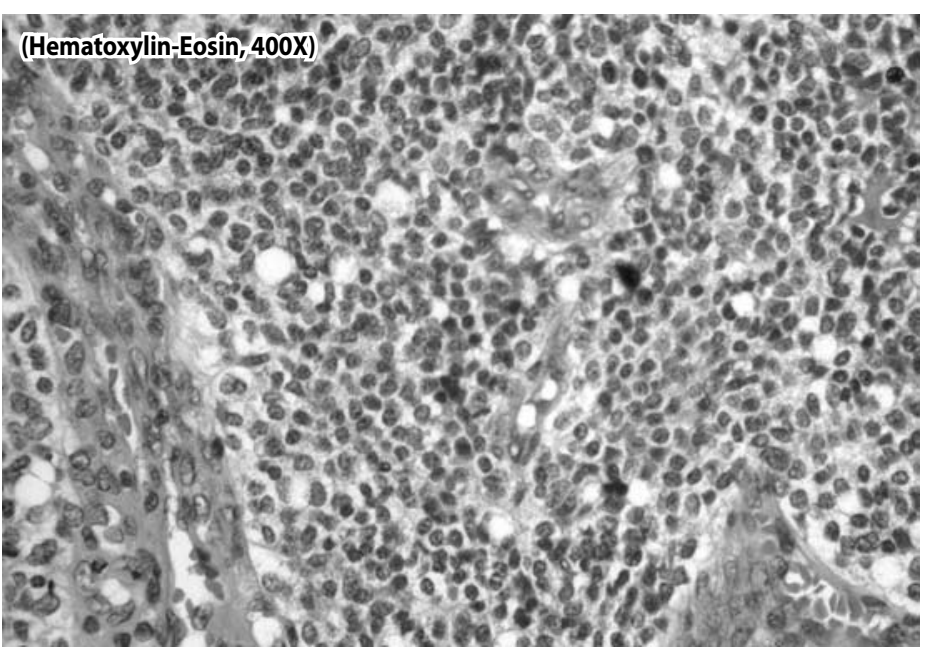

Figure 2. Case 1 - Uniform round nuclei with finely granular"salt-and-pepper" chromatin (HematoxylinEosin, 400X)

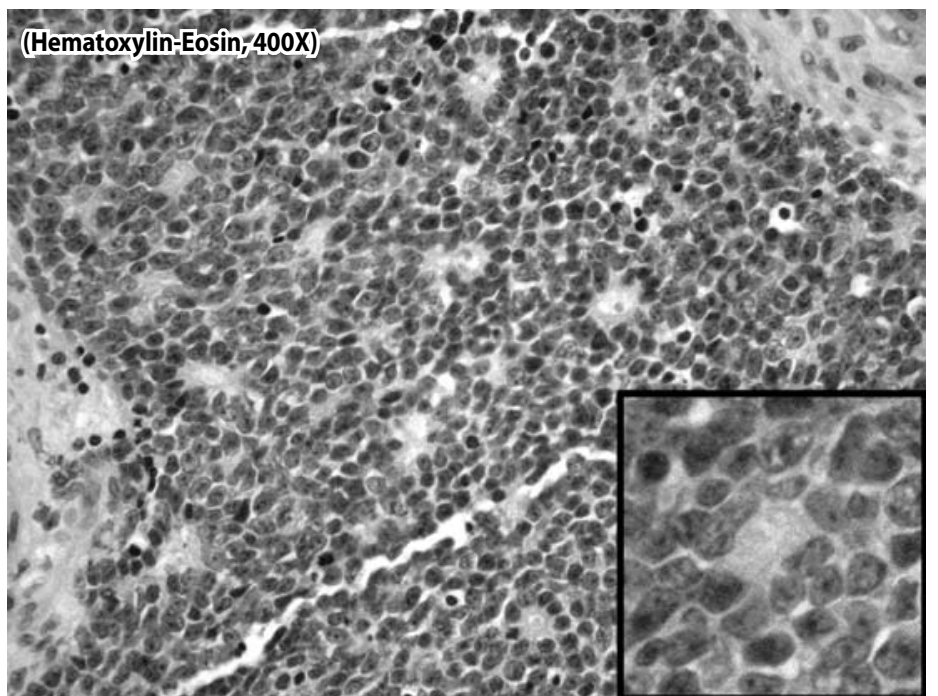

Figure 3. Case 1 - Homer-Wright pseudorosette: tumor cells surround a pseudolumen that contains neurofibrillary material (Hematoxylin-Eosin, 400X)

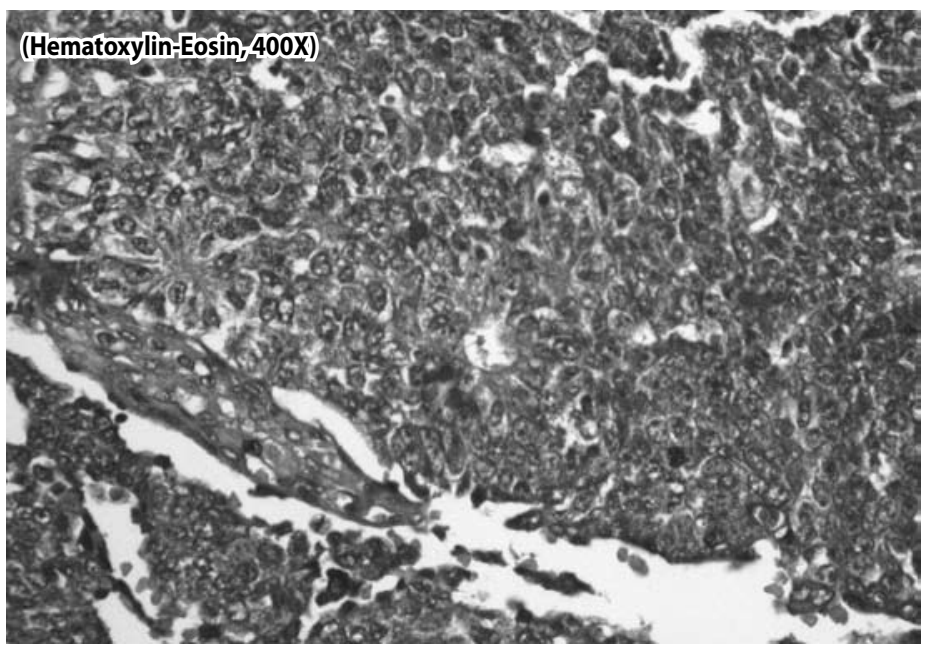

Figure 4. Case 2 - Flexner-Wintersteiner true rosette: tumor cells surround a true central lumen simulating a gland; note the nuclear pleomorphism (Hematoxylin-Eosin, 400X) 


\section{UNDER THE MICROSCOPE}

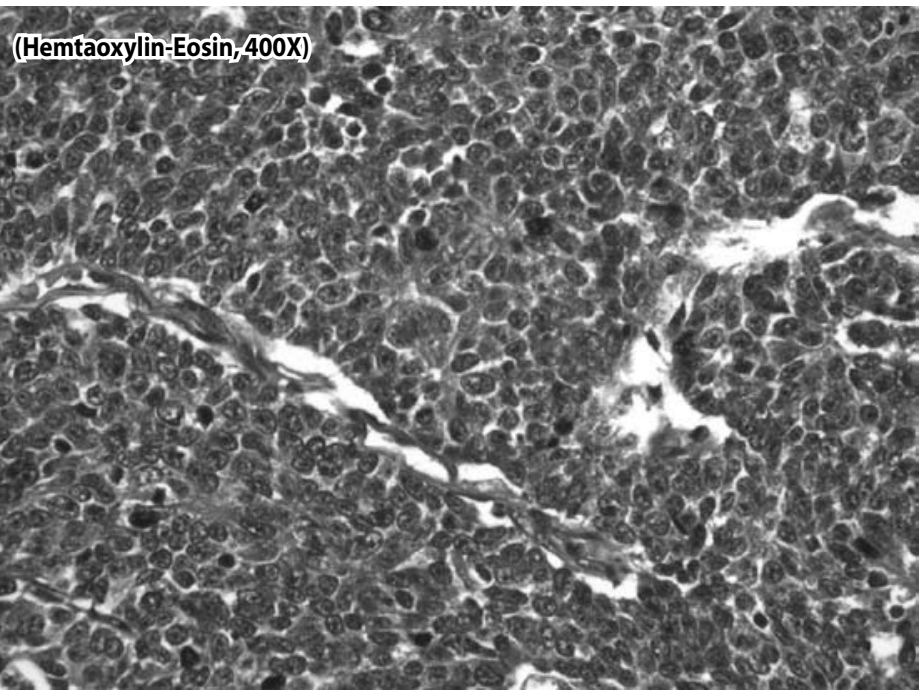

Figure 5. Case 2 - Nuclei that have more atypia and mitoses (Hemtaoxylin-Eosin, 400X)

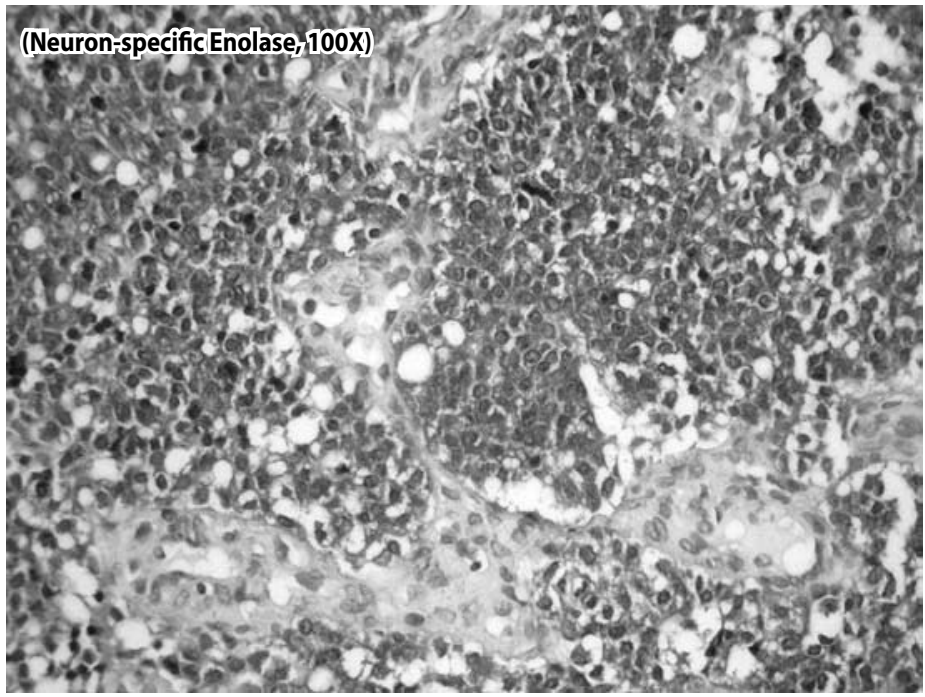

Figure 6. Archive case - Positive cytoplasmic reaction (Neuron-specific Enolase, 100X)

\section{ACKNOWLEDGMENT}

The author would like to acknowledge Drs. Ramon Antonio B. Lopa and Arsenio Claro A. Cabunca for the two cases and Drs. Treah May D. Suacillo and David Brian U. Olveda for the assistance in the pathologic sign-out and preparation of the microscopic images.

\section{REFERENCES}

1. Thompson LD. Malignant neoplasms of the nasal cavity, paranasal sinuses, and nasopharynx In: Thompson LD, ed. Head and Neck Pathology - Foundations in Diagnostic Pathology Series. Goldblum JR series ed. Churchill Livingstone Elsevier, Inc. 2006, p. 179 - 189.

2. Wenig BM, Dulguerov P, Kapadia SB, Prasad ML, Fanburg-Smith JC, Thompson LDR. Tumours of the nasal cavity and paranasal sinuses: Neuroectodermal tumours. In: Barnes EL, Eveson JW, Reichart P, Sidransky D, eds. Pathology and Genetics of Head and Neck Tumours, Kleihues $P$ Sobin LH, series eds. World Health Organization Classification of Tumors. Lyon, France: IARC Press; 2005: $65-75$.

3. Wenig B. Atlas of Head and Neck Pathology, $2^{\text {nd }}$ ed. Philadelphia: Elsevier - Saunders, Inc. 2008 p. $109-114$.

4. Prasad ML, Perez-Ordonez B. Nonsquamous lesions of the nasal cavity, paranasal sinuses, and nasopharynx. In Gnepp DR, ed. Diagnostic Surgical Pathology of the Head and Neck. Philadelphia: Saunders-Elsevier, 2009, p. 148 - 154. 